\title{
Local house prices, parental background and young adults' homeownership in England and Wales
}

\section{Abstract}

Financial constraints are thought to be making parental support an increasingly influential factor in the homeownership transitions of young Britons. This could inhibit social mobility, exacerbate the intergenerational transmission of wealth and deepen housing inequality. Although research shows that parental socio-economic advantage is associated with filial homeownership, less is known about whether these relationships are particularly pronounced in expensive housing markets where access to homeownership is often more constrained. This study tests this hypothesis by enriching the Office for National Statistics Longitudinal Study of England and Wales with data on local transactional house prices. Multilevel models indicate that disparities in the odds of homeownership between young adults with more and less socio-economically advantaged parents tend to deepen with increasing house prices. This pattern is most noticeable for women. However, parents and prices only intersect to greatly stratify the probability of homeownership when young adults' circumstances are otherwise conducive to owning.

\section{Key words}

Homeownership; house prices; intergenerational transmission; social stratification; young adults 


\section{Introduction}

In recent decades homeownership has become an increasingly significant factor in the economies and social policymaking of many Western countries. At the individual level entering homeownership is often a major life event which is usually thought to confer a range of benefits including improved prosperity, social status and dwelling and neighbourhood quality (Mulder et al., 2015). In some societies becoming a homeowner is also a social signifier of having navigated the transition to adulthood (Druta and Ronald, 2016). Policymakers are therefore concerned that an increasing proportion of young Europeans seem unable to access homeownership (Lennartz et al., 2015). This trend threatens to restrict social mobility and reshape the distribution of wealth between and within generations.

These issues have particular resonance in Britain, where the growing stratification of homeownership by age and birth cohort has become a key concern in housing policy debates. In The Pinch (2011), David Willetts posited that intergenerational wealth inequality is growing partly because a specific constellation of circumstances enabled many members of the Baby Boom cohort (born 1945-1965) to enter homeownership early in life. They then accumulated equity and 'insider advantages' as house prices inflated and homeownership became relatively less accessible to subsequent cohorts (Meen, 2013). In this view the declining accessibility of homeownership caused by rising prices and post-crisis credit constraints has intersected with broader demographic, educational and labour market trends to mean that young Britons and their continental peers spend longer renting or living with their parents (Andrew, 2012; Lennartz et al., 2015). 
Deepening economic constraints could also reshape which young people become homeowners. Fears are growing that high house prices and the more stringent financial requirements mortgage lenders have imposed since the Global Financial Crisis (GFC) may be making homeownership transitions more contingent on family support (McKee, 2012). Research shows that family and especially parental support - frequently supplied through financial transfers or guarantees, subsidised coresidence or 'in kind' assistance such as paying for shopping- is important when young adults first enter homeownership (Druta and Ronald, 2016; Heath and Calvert, 2013). This places children who cannot draw on parental support at a disadvantage in the housing market, potentially strengthening the intergenerational transmission of wealth and restricting social mobility. Literature from many Western countries supports this argument as children are typically more likely to become homeowners if their parents are advantaged in the labour force or own their dwelling (Di Salvo and Ermisch, 1997; Henretta, 1984; Lersch and Luijkx, 2015).

Although international comparisons suggest that the importance of family support varies with the affordability of owner-occupation (Mulder et al., 2015), surprisingly little is known about whether this is also the case within countries where the ease of accessing homeownership often also varies across space. If economic constraints make young adults' homeownership more dependent on family support then parental labour market and tenure position will, ceteris paribus, have closer links to the homeownership prospects of children living in areas with higher house prices (Tatch, 2007). This pattern could arise in two ways. On one hand children from less advantaged backgrounds who are committed to living in an expensive area (e.g. due to family responsibilities) may be more likely to rent, live at home or share their 
dwelling than their more advantaged peers. By contrast, less advantaged children who are more footloose or more driven to attain homeownership may be more likely than their more advantaged peers to selectively move to cheaper locations in order to buy. These processes could deepen inequality by restricting the locational options of children from less advantaged backgrounds and disproportionately excluding them from owner-occupation in expensive areas.

This study therefore asks are young adults' chances of homeownership more closely associated with the socio-economic position of their parents in places where house prices are high as compared with places where prices are lower? I focus on England and Wales as these countries have similar tenure structures and a largely shared history of housing policy. The paper begins by using life course theories to explain how parental socio-economic position may interact with local house prices to shape young adults' homeownership. I then outline the research design and discuss the results. I conclude with some broader reflections about housing careers and inequalities in young adulthood.

\section{Homeownership in young adulthood}

\section{Trends and preferences}

The proportion of young Britons entering owner-occupation has been falling since the late 1980s as people postpone homeownership (Andrew, 2012). Two sets of factors explain this trend. First, the transition to adulthood has become more protracted as young people spend longer in education and delay partnership and 
family formation (Berrington et al., 2009). This reduces their ability and inclination to take on the financial and locational commitments of homeownership. Second, young adulthood has become more economically precarious. Stubbornly high youth unemployment, student debt burdens, low incomes and job insecurity have combined with high housing costs, constrained access to credit and welfare retreat to make it harder for young people to muster the resources required by mortgage lenders (Andrew, 2012).

Despite these trends market research shows that most young Britons want to become homeowners, although many are unsure how long this will take (Jessop and Humphrey, 2014; Pannell, 2012). Ronald's (2008) work suggests that young adults' ownership preferences are holding up in the face of adversity partly because of the ideological power of homeownership. This ideology is maintained by taken-forgranted public discourses and private practices that normalise owner-occupancy by associating it with responsible citizenship, financial acumen and independence (Druta and Ronald, 2016). These discourses are bolstered by public expectations of rising house prices and the favourable economics of ownership, a lack of suitable rental alternatives, and policy interventions - such as Help to Buy ${ }^{1}$ - that support entry into homeownership (Ronald, 2008).

In Britain, public discussions about young adults' housing often focus on the causes and consequences of cohort trends, for example in debates about 'Generation Rent'. However, McKee (2012) argues that the processes currently deepening generational fractures may also be exacerbating the pre-existing patterns of housing inequality

\footnotetext{
${ }^{1}$ Help to Buy offers government backed equity loans, mortgage guarantees and savings products to assist prospective homeowners.
} 
within cohorts that are produced by persistent disparities in which young people become homeowners. Life course perspectives suggest that these disparities not only arise because of differences in life trajectories, but are also produced by the ways in which 'linked lives' and geographic factors come together to shape access to homeownership. These factors are now discussed in turn.

\section{The 'linked lives' of parents and children}

Researchers have long recognised that patterns of (dis)advantage pass down the generations through the housing system as parents shape the housing tenure, dwelling attributes and neighbourhood attainments of their children (Henretta, 1984; Sharkey, 2008). Mulder et al. (2015) outline several mechanisms that could explain why young adults in many countries are more likely to become homeowners if their parents are more advantaged in the labour market or own their dwelling (Aratani, 2011; Blaauboer, 2010; Di Salvo and Ermisch, 1997; Lersch and Luijkx, 2015; Öst, 2012). First, parents are likely to have more capacity to provide financial assistance if they have greater access to resources amassed through secure well-paid work or from the equity and lower housing costs that are often gained through owneroccupation (Mulder and Smits, 2013). In Britain, Jessop and Humphrey (2014) show that parents who help their children into homeownership are disproportionately drawn from advantaged socio-economic groups. These social patterns of assistance may also have geographic dimensions as parental access to resources (most notably housing equity) can be influenced by the characteristics of housing markets. 
Direct familial support for homeownership is often provided as gifts or loans towards mortgage deposits and lenders have been swift to incorporate this into their products and marketing (Helderman and Mulder, 2007; Tatch, 2007). Subsidised co-residence to allow saving and assistance with living costs are further ways in which more affluent parents can directly support the homeownership of their offspring (Druta and Ronald, 2016; Heath and Calvert, 2013). Such practices have come under greater scrutiny in the aftermath of the GFC amidst concern that affordability problems and credit barriers are lifting homeownership out of reach of young people whose families are unable or unwilling to provide support (NHF, 2014).

Parents may also indirectly influence the housing position of their children by shaping their human capital attainments, occupational trajectory and access to resources. Ermisch and Halpin (2004) note that well-documented intergenerational correlations in qualifications, occupational status and income mean that children from socio-economically advantaged backgrounds will typically be more likely to accumulate sufficient resources to enter homeownership than children from less advantaged backgrounds. This process could be bolstered by intergenerational transmissions of social capital, for example if advantaged parents provide their children with access to useful social networks and contacts. Controlling for young adults' life course development may therefore weaken the association between parental attributes and child homeownership.

Socialisation provides a third non-material mechanism linking tenure across generations. The idea is that homeowner parents influence the tenure preferences, expectations, cultural knowledge and perceptions of their children as they grow up in 
ways that lead them to eschew renting in favour of homeownership (Lersch and Luijkx, 2015). Status emulation and role model effects may play roles in this process (Henretta, 1984). Given the particularly strong British ideology of homeownership, it is unclear whether socialisation shapes young Britons' housing careers to the same extent as their continental peers.

Work by Blaauboer (2010) indicates that gender may configure how parental factors are linked to child homeownership. Using Dutch data she finds somewhat stronger parental effects for women than men. Gendered patterns of parental influence might arise because young men and women tend to have different housing trajectories as patterns of residence in the parental home, higher education enrolment, labour force participation, partnership formation and co-residence with children all vary by gender (Berrington et al., 2009; Ermisch, 1999). Moreover gendered norms and practicesfor example regarding caregiving and the maintenance of family networks- may influence locational choices, tenure preferences and the contact and emotional closeness of parents and children. This could influence whether children request housing assistance as well as parental perceptions of their need and desert.

Geographic factors

As educational and labour force transitions underpin much residential mobility in early adulthood, the geography of labour markets and educational institutions will configure young people's locational decisions and thus the spatial distribution of individuals who want and are able to access homeownership (Stockdale and Catney, 2014). At the national level Dennett and Stillwell (2010) show that young adults aged 
16-29 tend to flow into cities, while those aged 30-44 tend to counter-urbanise. These types of patterns may produce distinct but often hidden geographies of tenure preference as young people with different housing biographies and priorities choose to live in different areas over the life course. For example, highly qualified graduates who shared accommodation at university may disproportionately opt to subsequently live in opportunity rich urban centres and may also carry a preference for sharing flexible private rental housing into early adulthood (Heath and Kenyon, 2001). Moreover, the social selectivity of those moving longer distances to work or study means that the geography of labour markets and educational opportunities will also influence how young adults with sufficient resources to enter homeownership are distributed across space. Structural changes in labour markets and educational systems are therefore an important reason why patterns of early housing career development have changed considerably in recent decades.

Spatial variations in housing opportunities and constraints also shape young adults' homeownership. A good example of this is provided by Helderman and Mulder (2007), who show that intergenerational correlations of homeownership in the Netherlands originate in part because young people and their parents tend to live in close proximity under similar housing market conditions. Although there could be bidirectional links between housing opportunities and decisions about intergenerational proximity, Helderman and Mulder's work illustrates that young adults' homeownership is strongly shaped by the geography of housing systems.

The tenure composition of dwelling stock is likely to be an important geographic influence on young adults' homeownership (Helderman and Mulder, 2007). Areas 
with a greater proportion of rental dwellings are likely to have lower rates of young adult homeownership simply because they offer fewer opportunities to buy and also greater scope for living independently without owning. However, the UK has two distinct rental systems which may have differing links to young adults' homeownership. The social rental sector traditionally provided a secure, bureaucratically allocated, low-cost alternative to owner-occupation and thus more socially rented dwellings in an area might be associated with a lower probability of homeownership (Di Salvo and Ermisch, 1997). However, stock contraction means that demand for social housing now far exceeds supply in some parts of the country where tenancies are realistically accessible to only the most vulnerable (ONS, 2015). The proportion of socially rented dwellings in an area may therefore poorly reflect accessible vacancies. By contrast, abundant private rental housing in an area is likely to be negatively associated with young adults' homeownership. In these locations those who prioritise residential independence can rent privately, while those prioritising homeownership either stay in the parental home or move to less constrained markets.

The relative cost of owner-occupation is a second spatial influence on young adults' homeownership. In a cross-national analysis, Mulder and colleagues (2015) show that people are less likely to become homeowners when affordability is more constrained. Longitudinal evidence from 1990s Britain showed that high house prices increase parental co-residence and the age at which young people become homeowners (Andrew, 2012; Ermisch, 1999). This is because high house prices raise deposit requirements, affect the relative user costs of homeownership and can impede saving through correlation with higher rents (Andrew, 2012; Di Salvo and 
Ermisch, 1997; ONS, 2015). Places with high house prices also tend to have high price-to-earnings ratios and thus low long-term affordability (NHF, 2014).

Parents and prices

While there is growing evidence that 'linked lives' and geographic factors shape housing attainments in young adulthood, far less is known about how parents and prices interact to configure young people's homeownership. Intuition and international research suggest that parental socio-economic advantage may be especially relevant for young adults' homeownership where housing is more expensive and young people consequently need more help and to be more advantaged to overcome financial constraints (Mulder et al., 2015; Öst, 2012). Young people from less advantaged backgrounds who are committed to living in expensive areas may therefore be more likely to rent, share or live with parents than their more advantaged peers. In addition, young people from less advantaged backgrounds who are more footloose or particularly committed to homeownership may disproportionately opt to live in cheaper areas.

This suggests the hypothesis that lower parental socio-economic status has a stronger negative association with young adults' homeownership in areas with higher house prices. If this is the case then differential access to homeownership could be helping to polarise society by disproportionately excluding young people from less privileged backgrounds from owner-occupation in more prosperous parts of the country. This could have long-term implications for social mobility, migration behaviour and the distribution of wealth. 


\section{Data and methods}

\section{Longitudinal microdata}

This study uses the Office for National Statistics Longitudinal Study of England and Wales (LS). The LS is a relational database containing the linked census records of a $1 \%$ sample of the population of England and Wales. The original sample was selected from the 1971 census by incorporating data from all individuals born on one of four specific birth dates (Lynch et al., 2015). Immigrants and new babies with these birth dates are continuously added to the sample ${ }^{2}$. Census data from people living with Longitudinal Study Members (LSMs) are available, although these individuals are not followed through time. A key advantage of the LS is its low levels of attrition (Lynch et al., 2015).

Data were extracted from all LSMs aged 5-14 in 1991 (the 'baseline' census) who were usually resident in a private household with a parent. This age banding ensures that selected children were dependent on their parent(s) at baseline. Cases where the LSM was not in the LS in 2001 or 2011 (the 'outcome' census) were removed. After excluding a very small number of LSMs with missing data the final sample comprised 20230 men and 22080 women.

The dependent variable is a dummy identifying LSMs who were homeowners when aged $25-34$ in the 2011 census (43.0\% were homeowners). This was the modal age for first-time homeownership in the 1990s and 2000s (DCLG, 2011). LSMs were

\footnotetext{
${ }^{2}$ Immigrants enter the sample between censuses after registering with a General Practitioner.
} 
coded as homeowners if they were not co-resident with a parent and were living in an owner-occupied dwelling as the Household Reference Person (HRP) or their partner $^{3}$. HRP status is a census indicator derived using information from the household relationship grid on the census form (ONS, 2014). In each household people are first grouped into families headed by a Family Reference Person (FRP). Families are defined as either a co-resident couple; a couple with child(ren); a lone parent with child(ren); or grandparent(s) and grandchild(ren) if the intervening generation is absent. 'Children' can be of any age but cannot be living with a partner or child. The FRP is either the highest ranked partner or the lone (grand)parent in a family unit, with the ranking procedure sequentially using information on economic activity, age and census form order. In households with families the highest ranked FRP is HRP. In households without families the HRP is the highest ranked individual. Experiments using alternative dependent variables coded only using tenure and either HRP status or household relationships produced very similar results to those reported below.

The key independent variables are parental labour force position and housing tenure in 1991. These indicators of parental socio-economic status proxy tenure socialisation and the indirect transmission of homeownership through socioeconomic attainments. Although the LS does not record financial transfers, prior evidence suggests that their effects should be absorbed by the parental measures as the likelihood of intergenerational transfers is usually greater when parents own their dwelling and have more advantaged occupations (Jessop and Humphrey, 2014; Mulder and Smits, 2013). More positively, the parental variables should help to

\footnotetext{
${ }^{3}$ Unfortunately it is tricky to tell 'who lives with who' using census data. Given the age of sample members it seems reasonable to assume that those living with a parent are in the parental home.
} 
capture how children's homeownership might be influenced by their perceptions of potential support, as well as by non-financial assistance. As it is not possible to disentangle these mechanisms the results of this study should nonetheless be interpreted cautiously in terms of associations rather than causal effects.

Parental labour force position is derived using the employment status of the LSM's parent(s) and the approximated National Statistics Socio-Economic Classification (NS-SEC) of working parents. NS-SEC classifies occupations according to employment relations and conditions. Where both parents are employed the 'higher' occupational class is assigned and the three category version of NS-SEC is used to avoid small cell counts. This coding separates parents employed in higher managerial, administrative and professional occupations (NS-SECs 1-2) from those working in intermediate jobs (NS-SECs 3-4) and routine and manual occupations (NS-SECs 5-7). Workless parents received a separate code. Parental tenure is a dummy separating owners from tenants. Extra controls were defined for other personal and parental attributes known to configure housing careers (Appendix A1 for summaries).

Housing market indicators

Data capturing housing market conditions in the local authority district $^{4}$ (henceforth district) of residence were attached to LSMs. There were 348 districts in England and Wales in 2011, although only 347 are present in the sample. Districts are used pragmatically to approximate local housing markets as this is the finest granular

\footnotetext{
${ }^{4}$ Median 2011 population $=126000$.
} 
scale for which robust data on house prices can currently be attached to the $\mathrm{LS}^{5}$. While this approach allows us to observe the local price variations missed by regional analysis, it is important to recognise that the geography of housing markets may not respect administrative boundaries.

Two sets of district housing market characteristics were attached. First, 2011 census data were used to measure the percentage of households renting from social and private landlords. Second, information on median 2011 house prices was obtained from the Office for National Statistics House Price Statistics for Small Areas. Median prices are based on market transactions recorded by the Land Registry. In 2011 transactions were below pre-crisis levels while prices were falling in cheaper areas and rising in expensive locations (ONS, 2015). The median price of terraced houses is used as the price indicator to take into account - insofar as is possible with the available data- that the composition of dwelling types may vary across districts. The price of terraced housing is also particularly relevant for resource strapped young people as median terraced house prices were on average well below overall median prices in 2011.

Median prices were used to divide districts into deciles. Tied values mean these do not contain identical numbers of districts. Prices were log transformed for modelling work to reduce skewness. Table 1 provides summary information about the deciles. The first columns show that the decile distribution of sample members largely follows the overall population distribution. The second set of columns show the regional geography of 2011 house prices. Northern and Welsh districts were concentrated in

\footnotetext{
${ }^{5}$ Finer grained geographies are available but are too small to approximate housing markets and many have very few housing transactions.
} 
the cheaper deciles while Southern districts had higher prices. Most districts in the top decile are London boroughs.

*** Table 1 about here ***

As incomes vary spatially and affect the extent to which house prices constrain homeownership, further work was conducted to establish whether the district house price variable also captures variation in the long-term affordability of homeownership. Affordability is often defined as the ratio of prices to incomes. Analysis of ONS data comparing district median house prices to estimated average earnings showed that median price to income ratios increase monotonically across the deciles in Table 1 from 5.3 in the lowest decile to 11.2 in the highest. There is also a very strong Spearman's rank correlation between district median prices and average price to income ratios $(\rho=0.88, p<0.001)$. Median terraced house prices thus appear to be a crude but simple composite indicator of the broad cost and affordability of homeownership.

Analysis

The analysis begins by plotting the proportion of young adults in each decile who were homeowners by parental background. Concentrating on differences within deciles takes into account that the proportion of children living in each decile could vary by family background because children often live relatively near to their parents. Comparing the conditional effects of parental background thus gives a good indication of whether young people from less advantaged backgrounds are 
disproportionately less likely to be homeowners when living in more expensive places.

Multilevel logistic regression models were then estimated to examine how parents and prices are linked to homeownership in young adulthood after controlling for young people's personal attributes, position in various life course careers and the characteristics of their district. In these models LSMs are nested within districts ${ }^{6}$. All models were fitted in Stata 12 using adaptive quadrature methods. All analyses were split by gender as differences in male and female labour force participation, living arrangements and use of welfare support may affect the likelihood of homeownership and the importance of parental background (Blaauboer, 2010).

\section{Results}

Figure 1a shows the proportion of sample members in owner-occupation in 2011 by district house price decile and parental labour force position ${ }^{7}$. Overall a higher proportion of young women (45.7\%) than men (40.1\%) are homeowners, probably because women tend to partner slightly older men. For both genders and across all deciles children whose parents worked in managerial, administrative and professional occupations (NS-SEC 1-2) are significantly more likely to be homeowners than those whose parents had routine or manual jobs (NS-SEC 5-7). Children with workless parents are the least likely to own their dwelling.

\footnotetext{
${ }_{7}^{6}$ Means $=58$ men and 64 women per district.

${ }^{7}$ Points for children whose parents worked in intermediate (NS-SEC 3-4) occupations are not shown as this category is heterogeneous. Their proportions follow the patterns shown in Figure 1a.
} 
If the hypothesis holds then differences in the homeownership rates of young adults from more and less advantaged backgrounds should widen as house prices increase. Figure 1a suggests this is not the case as across all groups the homeownership rate generally falls at a roughly similar rate with increasing house prices. For most groups (especially women with parents in NS-SEC 1-2), the drop in homeownership is especially noticeable in the most expensive decile.

Figure $1 \mathrm{~b}$ replaces parental labour force position with parental tenure. In all deciles the homeownership rate is significantly lower for children whose parents were tenants rather than owner-occupiers. Interestingly, the magnitude of this disparity is relatively constant across the deciles and if anything appears smallest in the most expensive districts where comparatively few young people are homeowners.

To explore whether these patterns vary within young adulthood further analyses (not shown) reran Figures 1a and 1b separately for LSMs aged 25-29 and 30-34. Although the same basic patterns were evident for both groups, the relative gap between children from more and less advantaged backgrounds was typically somewhat greater for the older cohort. This suggests that parental advantage increases the odds more than the speed of entering owner-occupancy (Di Salvo and Ermisch, 1997). This could be because young people from more advantaged backgrounds often voluntarily postpone homeownership while attending higher education and establishing careers. 
Table 2 presents four well-fitting random intercepts logistic regression models testing how parental background and district house prices are associated with young adults' homeownership after controlling for other factors. All models contain identical variables but Models $1 \mathrm{a}$ and $1 \mathrm{~b}$ interact parental labour force position with district house prices, while Models $2 \mathrm{a}$ and $2 \mathrm{~b}$ repeat the interaction for parental housing tenure. The estimated Variance Partition Coefficients indicate that there is very little unexplained district level variation in young adults' homeownership. In consequence, there is negligible difference between the cluster-specific results presented and population-averaged results.

*** Table 2 about here ${ }^{* \star *}$

The effects of the control variables are largely as expected. Homeownership becomes more common as age increases but at a diminishing rate. Asian men have significantly lower odds of homeownership than their White British peers, while the opposite is true for Asian and non-British White women. Good health, higher education and living with children in 2011 increase the relative odds of homeownership. Interestingly, having lived with children in 2001 is associated with reduced odds of owner-occupation in 2011. This might be because early childbearing hinders resource accumulation and may grant young people priority access to scarce social housing. Having lived with a partner in 2001 boosts female homeownership while men are less likely to own if they were resident in the parental home in 2001. Being single, living in a couple with fewer earners and having a less advantaged occupation are all associated with substantially lower odds of 
homeownership relative to dual-earner couples with a high occupational class position.

Recent migration is linked to lower odds of homeownership. This is probably the combined result of transaction costs, expectations of future residential mobility and a reluctance to commit to homeownership in unfamiliar areas. Neither parental age nor most of the regional dummies have particularly significant effects. At the district level young adults are more likely to be homeowners in urbanized areas and in places with less rental stock (especially in the private sector) ${ }^{8}$. The former result may suggest that higher turnover in urban areas creates more opportunities for young people to enter homeownership.

Models $1 \mathrm{a}$ and $1 \mathrm{~b}$ interact parental labour force position with district house prices. This means that the 'main effect' of each interacted variable must be interpreted as its effect when the other is 0 (ie the NS-SEC 1-2 reference category or the mean district house price). For both genders higher prices are associated with lower odds of homeownership amongst young people whose parents worked in NS-SEC 1-2. In districts with mean prices young people are significantly less likely to be homeowners if their parents worked in NS-SEC 5-7 occupations or were not working. The interaction effects suggest that higher house prices deepen these disparities in the relative odds of homeownership by parental background, most notably amongst women.

\footnotetext{
${ }^{8}$ One referee noted that tenure mix predictors may be endogenous. Re-fitting the models without these variables indicates that they do not introduce bias as the results are virtually identical. Models incorporating tenure mix are reported as they fit slightly better, reduce unexplained district level variance and provide tentative evidence about how housing stock composition is linked to young adults' homeownership.
} 
Models $2 \mathrm{a}$ and $2 \mathrm{~b}$ show that in districts with average house prices young people whose parents were tenants have substantially lower odds of homeownership than young people whose parents were owner-occupiers. Higher house prices are associated with lower odds of homeownership amongst the children of owneroccupiers. There is no significant multiplicative interaction effect for men in Model 2a. By contrast, Model $2 \mathrm{~b}$ shows that the relative odds that young women are homeowners become less favourable to the children of tenants as house prices increase. In general these results broadly support the hypothesis that lower parental socio-economic status has a stronger negative association with young adults' homeownership in areas with higher house prices. This is especially true for women.

To examine the interaction effects in terms of absolute differences in probability, Figures $2 \mathrm{a}$ and $2 \mathrm{~b}$ use Models $1 \mathrm{a}$ through $2 \mathrm{~b}$ to plot the predicted probability that two hypothetical individuals are homeowners while varying their gender, district house price and parental background. Profile A's other personal attributes and district characteristics are fixed to generally favour homeownership, while Profile B is fixed to have fewer individual advantages and face greater district constraints. These representative profiles were chosen because further simulations indicated that the ways in which parental background and district house prices intersect to shape the probability of homeownership depends especially strongly on whether young adults' other circumstances generally favour owner-occupation. In all plots district house prices are shown on the log scale with the deciles from Table 1 superimposed. The $x$ axis is truncated at 14 as only Westminster and Kensington and Chelsea have prices above this level ${ }^{9}$.

\footnotetext{
${ }^{9}$ Excluding these outliers yields very similar model estimates.
} 
${ }^{* * *}$ Figures $2 \mathrm{a}$ and $2 \mathrm{~b}$ about here ${ }^{* * *}$

The Profile $B$ lines in Figures $2 a$ and $2 b$ show that when young adults face many restrictions and constraints then their predicted probability of homeownership is low regardless of parental background or district house price. For young people in more auspicious circumstances (Profile A), the plots show that the predicted probability of homeownership typically falls as house prices increase. However, this effect should not be overstated as it takes a considerable increase in district house prices to greatly reduce the probability of homeownership.

More advantaged young adults (Profile A) are considerably less likely to be homeowners if their parents rented rather than owned their dwelling. By contrast, the stratifying effect of parental labour force position is more muted. Figures $2 a$ and $2 b$ also show that the predicted probability of homeownership declines particularly rapidly as house prices rise for Profile A children with less advantaged parents. This pattern of divergence is especially noticeable for women.

Taken together, the results partly indicate that parental socio-economic position is generally more important for child homeownership in areas with higher house prices. Two qualifications to this pattern must however be emphasised. First, the hypothesised interaction between parents and prices is more noticeable for women than men. Second, parents and prices only intersect to substantially influence the absolute probability that more advantaged young adults are homeowners. Neither disparities in house prices nor parental attributes do much to stratify the 
homeownership prospects of children when other factors mean that they are unlikely to enter owner-occupation.

\section{Conclusions}

In many countries the growing difficulty of accessing homeownership is reshaping young people's housing careers and transitions to adulthood. These trends may not only create generational friction but could also deepen the divide between young people from more and less advantaged backgrounds (McKee, 2012). This could limit social mobility and increase the intergenerational transmission of wealth and (dis)advantage, especially in places where house prices are high and financial constraints more strongly restrict access to homeownership. Taking England and Wales as case studies, this paper has examined how parental socio-economic status and local house prices intersect to shape young adults' homeownership.

The results show that young adults' homeownership is geographically uneven and related to local variations in house prices. Young people from all social origins have lower odds of homeownership when house prices are high and rates of owneroccupation are especially low in the most expensive districts. While this suggests that higher house prices constrain access to owner-occupation, the models emphasise that socio-demographic attributes and labour force participation are

critically important predictors of young adults' homeownership. House price inflation is therefore only one of many structural reasons why young Britons are delaying homeownership (Andrew, 2012). 
'Linked lives' matter for young adults' homeownership as the children of tenants and those whose parents had a less favourable labour force position are generally less likely to own than children from more advantaged families. This cannot be completely explained by observable differences in life course trajectories, indicating that socialisation and/or resource transmission channel (dis)advantage down the generations through the housing system in Britain as in other Western countries. In the long-term this could restrict social mobility as young people from less advantaged backgrounds are disproportionately unlikely to enter homeownership. Moreover, the contraction of the social housing sector means that there is no longer an affordable and secure rental option for all but the most vulnerable young people. This means that those unable to access homeownership have to remain in the parental home, share or rely on weakly regulated privately rented accommodation that is often relatively costly, insecure and of poorer quality. This housing marginality will be disproportionately experienced by the least affluent and those from less advantaged backgrounds who are also bearing the brunt of austerity policies and recent welfare reforms.

The results only partially support the hypothesis that parental socio-economic advantage is especially relevant for young people's homeownership in more expensive locales. On one hand there is greater disparity in the odds of homeownership between children from more and less advantaged backgrounds in areas with higher house prices. However, these relative differentials only translate into increasingly stratified probabilities of homeownership across the house price gradient when young people's life course trajectories and location are otherwise conducive to owner-occupancy. For young people in less favourable circumstances 
neither parents nor prices have much effect on their (low) probability of homeownership. This suggests that young adults from less privileged backgrounds may face cumulative disadvantages in the housing system as their homeownership prospects are first limited by intergenerational continuities in life course trajectories, and then by more direct parental effects which seem particularly potent in expensive housing markets. Housing policy interventions are therefore unlikely to create a more socially mobile and equitable housing system unless efforts are also made to tackle persistent inequalities in the educational system and labour market.

There are several potential reasons why the hypothesis seems to hold more strongly for women than men. First, young men could be less prone to receive parental support, although Mulder and Smits (2013) do not find this to be true in the Netherlands. Second, the stratification of homeownership may accumulate as young adulthood progresses if children from more advantaged backgrounds are particularly likely to defer owner-occupancy. As women tend to partner older men and pass more rapidly into adulthood the observed gender differences could thus be a 'stage' rather than gender effect. Finally, it may be that young men from less advantaged backgrounds are more driven to enter homeownership. This could be for reasons of status display or because less advantaged women living in expensive areas are more likely to have priority access to social housing than their male counterparts as they are more likely to live with children. Disentangling these explanations requires longitudinal surveys with frequent observations, rich information about (time-varying) parental attributes and data on intergenerational exchanges. 
This study also suggests several broader avenues for further research. First, scholars could test whether the links between parental background and young adults' homeownership vary at different spatial scales. Although the data requirements are formidable, geographical variations could also be more richly explored by considering the relative locations of both parents and children, as well as by jointly examining tenure and locational decisions. Finally, we also need to know whether inequalities in young adults' homeownership accumulate, stabilise or wear off as they age. This is important for understanding how housing opportunities are shaped by period and cohort effects. Many individuals in the cohort examined in this paper will have been considering first-time homeownership at the same time as the GFC was reducing housing transactions, increasing borrowing constraints and generating labour market uncertainty. Testing how the crisis and the austerity policies implemented in its aftermath are reshaping housing inequality remains a crucial objective for longitudinal research. 


\section{Acknowledgements}

This research was supported by an Economic and Social Research Council (ESRC) Future Research Leaders award [ES/L009498/1]. Additional financial support was provided by the Isaac Newton Trust.

The permission of the Office for National Statistics (ONS) to use the Longitudinal Study is gratefully acknowledged, as is the invaluable help provided by staff of the Centre for Longitudinal Study Information \& User Support (CeLSIUS). CeLSIUS is supported by the ESRC Census of Population Programme [ES/K000365/1]. The author is solely responsible for all analyses and interpretations of the data.

This work contains statistical data from ONS which is Crown Copyright. The use of the ONS statistical data in this work does not imply the endorsement of the ONS in relation to the interpretation or analysis of the statistical data. This work uses research datasets which may not exactly reproduce National Statistics aggregates.

I would like to thank Bill Clark, Michael Oxley and two anonymous reviewers for their comments on earlier versions of this paper. 


\section{References}

Andrew M (2012) The changing route to owner-occupation: The impact of borrowing constraints on young adult homeownership transitions in Britain in the 1990s. Urban Studies 49(8): 1659-1678.

Aratani $Y$ (2011) Socio-demographic variations of homeowners and differential effects of parental homeownership on offspring's housing tenure. Housing Studies 26(5): 723-746.

Berrington A, Stone J and Falkingham J (2009) The changing living arrangements of young adults in the UK. Population Trends 138(Winter): 27-37.

Blaauboer M (2010) Family background, individual resources and the homeownership of couples and singles. Housing Studies 25(4): 441-461.

Dennett A and Stillwell J (2010) Internal migration in Britain 2000-01, examined through an area classification framework. Population, Space and Place 16(6): 517538.

Department for Communities and Local Government (DCLG) (2011) Live Table 537. Housing market: Distribution of borrowers' ages by new/other dwellings and type of buyer, United Kingdom, from 1990. Available at: <https://www.gov.uk/government/ statistical-data-sets/live-tables-on-housing-market-and-house-prices> (accessed 27/07/16). 
Di Salvo P and Ermisch J (1997) Analysis of the dynamics of housing tenure choice in Britain. Journal of Urban Economics 42: 1-17.

Druta O and Ronald R (2016) Young adults' pathways into homeownership and the negotiation of intra-family support: A home, the ideal gift. Sociology. DOI: 10.1177/0038038516629900.

Ermisch J (1999) Prices, parents, and young people's household formation. Journal of Urban Economics 45(1): 47-71.

Ermisch $\mathrm{J}$ and Halpin B (2004) Home ownership and social inequality in Britain. In Kurz $\mathrm{K}$ and Blossfeld H-P (eds) Home Ownership and Social Inequality in Comparative Perspective. Stanford: Stanford University Press, pp. 255-280.

Heath S and Calvert E (2013) Gifts, loans and intergenerational support for young adults. Sociology 47(6): 1120-1135.

Heath S and Kenyon L (2001) Single young professionals and shared household living." Journal of Youth Studies 4(1): 83-100.

Henretta J (1984) Parental status and child's home ownership. American Sociological Review 49(1): 131-140. 
Helderman A and Mulder C (2007) Intergenerational transmission of homeownership: The roles of gifts and continuities in housing market characteristics. Urban Studies 44(2): 231-247.

Jessop C and Humphrey A (2014) Generation Rent: Perceptions of the First-time Buyer Market. London: NatCen/Halifax. Available at:

<http://www.natcen.ac.uk/our-research/research/the-reality-of-generation-rent/> (accessed 27/07/16).

Lennartz C, Arundel R and Ronald R (2015) Younger adults and homeownership in Europe through the Global Financial Crisis. Population, Space and Place. DOI: 10.1002/psp.1961.

Lersch PM and Luijkx R (2015) Intergenerational transmission of homeownership in Europe: Revisiting the socialisation hypothesis. Social Science Research 49: 327342

Lynch K, Leib S, Warren J, Rogers N and Buxton J (2015) Longitudinal Study 2001 2011: Completeness of Census Linkage. Office for National Statistics. Available at: <https://www.ons.gov.uk/aboutus/whatwedo/paidservices/longitudinalstudyls> (accessed 27/07/16).

McKee K (2012) Young people, homeownership and future welfare. Housing Studies 27(6): 853-862. 
Meen G (2013) Homeownership for future generations in the UK. Urban Studies 50(4): 637-656.

Mulder CH, Dewilde C, van Duijn M and Smits A (2015) The association between parents' and adult children's homeownership: A comparative analysis. European Journal of Population 31(5): 495-527.

Mulder CH and Smits A (2013) Inter-generational ties, financial transfers and homeownership support. Journal of Housing and the Built Environment 28(1): 95-112.

National Housing Federation (NHF) (2014) Broken Market, Broken Dreams: Home Truths 2014/2015. London: National Housing Federation. Available at: <http://www.housing.org.uk/topics/research/home-truths/> (accessed 27/07/16).

Office for National Statistics (ONS) (2015) Housing Summary Measures Analysis. Newport: ONS. Available at: <http://www.ons.gov.uk/ons/rel/regionalanalysis/housing-statistics-portal/housing-summary-measures/rpt.html> (accessed 27/07/16).

ONS (2014) 2011 Census Glossary of Terms. Newport: ONS. Available at: <https://www.ons.gov.uk/census/2011census/2011censusdata/2011censususerguid e/glossary > (accessed 27/07/16). 
Öst CE (2012) Parental wealth and first-time homeownership: A cohort study of family background and young adults' housing situation in Sweden. Urban Studies 49(10): 2137-2152.

Pannell B (2012) Maturing attitudes to home-ownership. Housing Finance (2): 1-14.

Ronald R (2008) The Ideology of Home Ownership: Homeowner Societies and the Role of Housing. Basingstoke: Palgrave Macmillan.

Sharkey P (2008) The intergenerational transmission of context. American Journal of Sociology 113(4): 931-969.

Stockdale A and Catney G (2014) A life course perspective on urban-rural migration: The importance of the local context. Population, Space and Place 20(1): 83-98.

Tatch J (2007) Affordability_are parents helping? Housing Finance (3): 1-11.

Willetts D (2011) The Pinch: How the Baby Boomers Took Their Children's FutureAnd Why They Should Give It Back. London: Atlantic Books. 
Figures and tables

Figure 1a. Proportion of young adults in homeownership by parental labour force position and district house price decile

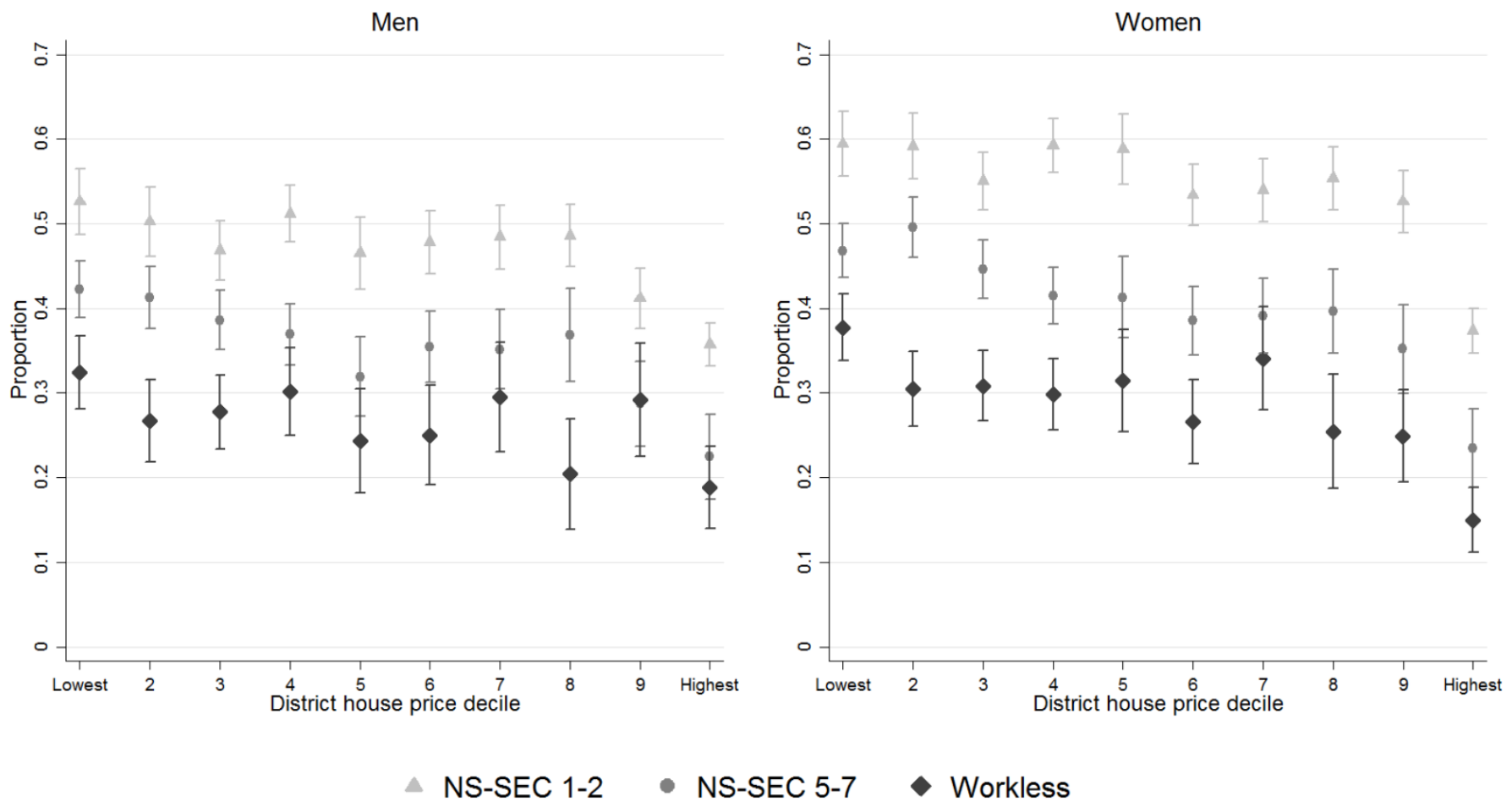

Figure 1b. Proportion of young adults in homeownership by parental tenure and district house price decile
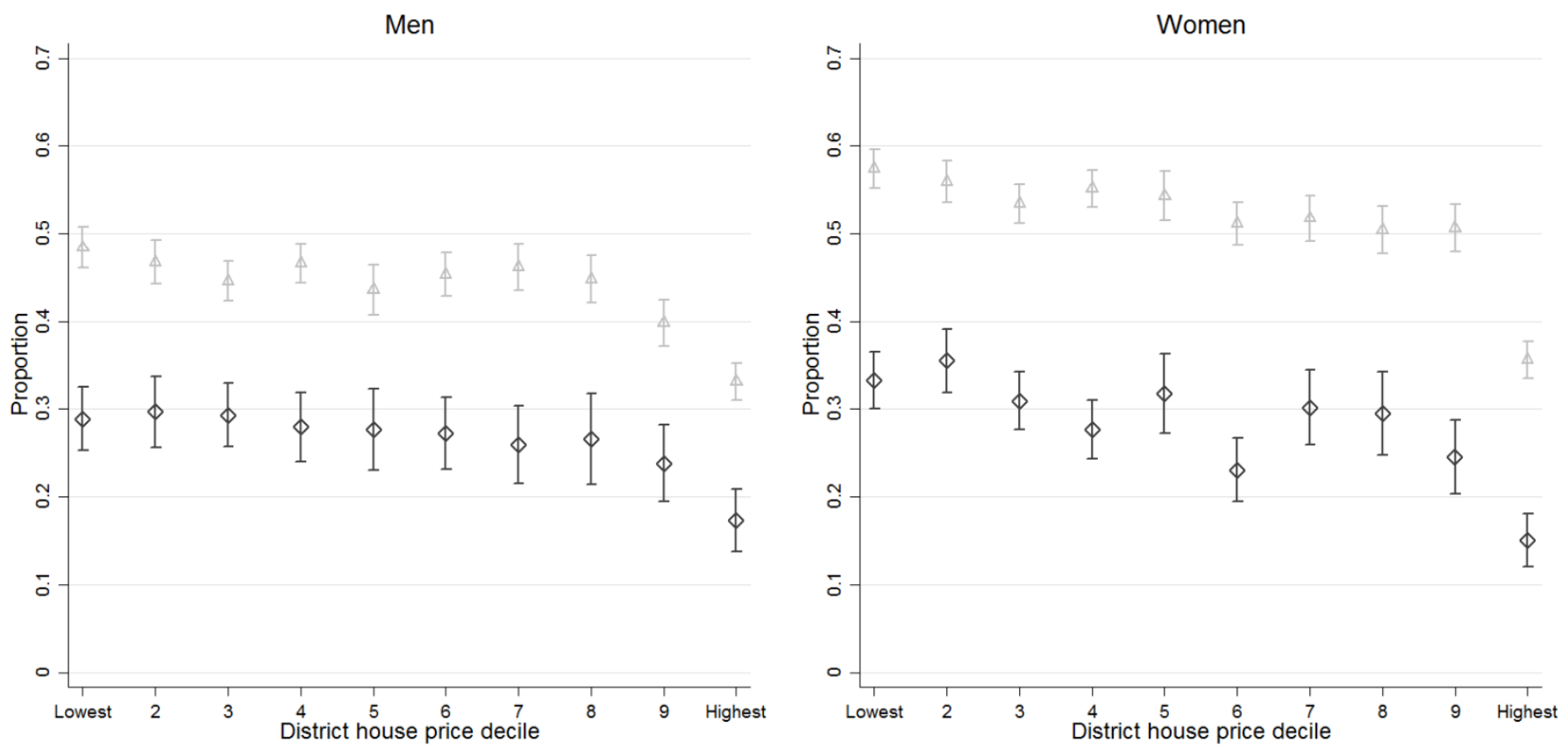

$\triangle$ Owner-occupation $\diamond$ Tenancy

Source: ONS LS, own analysis. 95\% confidence intervals. 
Figure 2a. Predicted probability of homeownership by parental labour force position and median district house price

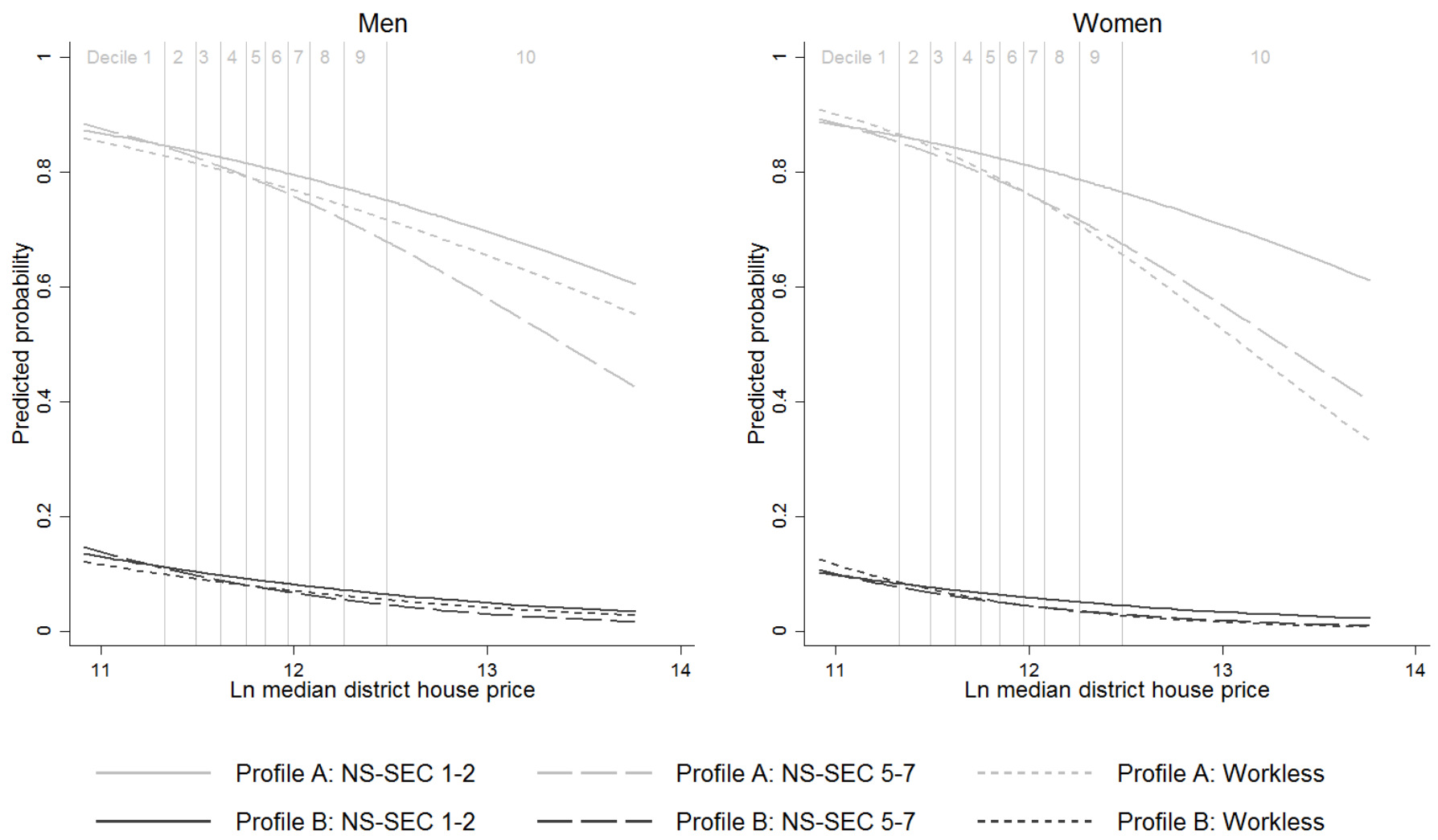

Figure 2b. Predicted probability of homeownership by parental tenure and median district house price
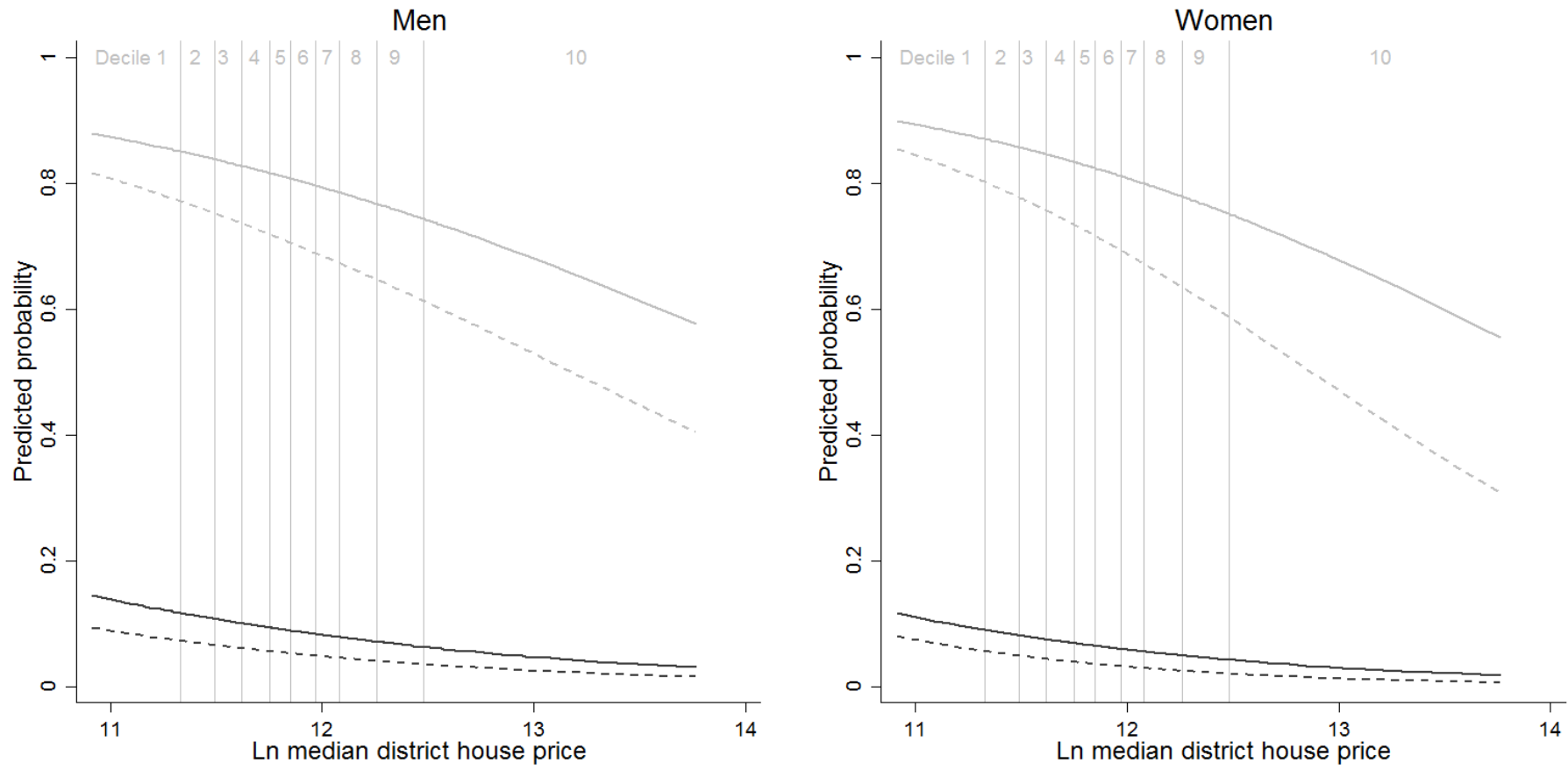

Profile A: Owner-occupation

Profile A: Tenancy

Profile B: Owner-occupation

Profile B: Tenancy

Source: ONS LS, own analysis. Random effects set to 0 . 
Table 1. Characteristics of district house price deciles

\begin{tabular}{|c|c|c|c|c|c|c|c|c|c|c|c|c|}
\hline \multirow[t]{2}{*}{ Decile } & \multirow[t]{2}{*}{$n$} & \multicolumn{2}{|c|}{$\%$ of men in decile } & \multicolumn{2}{|c|}{$\%$ of women in decile } & \multicolumn{4}{|c|}{$\%$ of districts in decile } & \multicolumn{3}{|c|}{ District house prices $(£)$} \\
\hline & & LSMs & Population & LSMs & Population & North & Mid \& E & South & Wales & Minimum & Median & Maximum \\
\hline 1 (low) & 36 & 11.9 & 11.5 & 12.1 & 11.4 & 37.5 & 4.3 & 0.0 & 18.2 & $\begin{array}{c}55000 \\
\text { (Burnley) }\end{array}$ & 76250 & $\begin{array}{c}83000 \\
\text { (Liverpool) }\end{array}$ \\
\hline 2 & 34 & 9.9 & 9.7 & 10.4 & 9.7 & 18.1 & 12.8 & 0.0 & 27.3 & $\begin{array}{c}83500 \\
\text { (Bassetlaw) }\end{array}$ & 90125 & $\begin{array}{c}97000 \\
\text { (Newark and Sherwood) }\end{array}$ \\
\hline 3 & 35 & 12.3 & 11.9 & 12.3 & 11.9 & 19.4 & 13.7 & 0.0 & 22.7 & $\begin{array}{c}97250 \\
\text { (Walsall) }\end{array}$ & 102000 & $\begin{array}{c}110000 \\
\text { (Leicester) }\end{array}$ \\
\hline 4 & 40 & 12.2 & 12.6 & 12.9 & 12.6 & 9.7 & 22.2 & 2.2 & 18.2 & $\begin{array}{c}110995 \\
\text { (South Derbyshire) }\end{array}$ & 118500 & $\begin{array}{c}125000 \\
\text { (Charnwood) }\end{array}$ \\
\hline 5 & 30 & 7.4 & 7.4 & 7.2 & 7.4 & 5.6 & 12.0 & 7.3 & 9.1 & $\begin{array}{c}126500 \\
\text { (Swindon) }\end{array}$ & 134250 & $\begin{array}{c}140000 \\
\text { (Huntingdonshire) }\end{array}$ \\
\hline 6 & 38 & 9.8 & 9.6 & 9.9 & 9.6 & 5.6 & 11.1 & 14.6 & 4.5 & $\begin{array}{l}140250 \\
\text { (Torbay) }\end{array}$ & 150000 & $\begin{array}{l}155000 \\
\text { (Solihull) }\end{array}$ \\
\hline 7 & 32 & 8.7 & 8.4 & 8.5 & 8.4 & 4.2 & 9.4 & 13.1 & 0.0 & $\begin{array}{c}157950 \\
\text { (Derbyshire Dales) }\end{array}$ & 168000 & $\begin{array}{l}176000 \\
\text { (Dartford) }\end{array}$ \\
\hline 8 & 34 & 7.9 & 7.8 & 7.6 & 7.9 & 0.0 & 4.3 & 21.2 & 0.0 & $\begin{array}{c}177000 \\
\text { (New Forest) }\end{array}$ & 189975 & $\begin{array}{c}210000 \\
\text { (Horsham) }\end{array}$ \\
\hline 9 & 36 & 8.3 & 9.1 & 7.9 & 9.1 & 0.0 & 8.5 & 19.0 & 0.0 & $\begin{array}{l}211000 \\
\text { (Cotswold) }\end{array}$ & 228250 & $\begin{array}{c}250000 \\
\text { (Waltham Forest) }\end{array}$ \\
\hline 10 (high) & 33 & 11.5 & 12.1 & 11.2 & 12.0 & 0.0 & 1.7 & 22.6 & 0.0 & $\begin{array}{l}263750 \\
\text { (Oxford) } \\
\end{array}$ & 339000 & $\begin{array}{c}2350000 \\
\text { (Kensington and Chelsea) }\end{array}$ \\
\hline
\end{tabular}

Sources: Columns 3 and 5 from ONS LS (own analysis); columns 4 and 6 from 2011 census, columns 11 to 13 from ONS House Price Statistics for Small Areas.

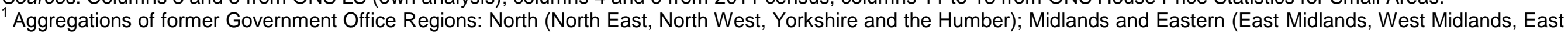
of England); South (London, South East; South West); Wales. 
Table 2. Multilevel logistic regression models of homeownership in young adulthood

\begin{tabular}{|c|c|c|c|c|c|c|c|c|}
\hline \multirow[t]{3}{*}{ Variables } & \multicolumn{4}{|c|}{ Parental labour force position } & \multicolumn{4}{|c|}{ Parental housing tenure } \\
\hline & \multicolumn{2}{|c|}{ Model 1a. Men } & \multicolumn{2}{|c|}{ Model 1b. Women } & \multicolumn{2}{|c|}{ Model 2a. Men } & \multicolumn{2}{|c|}{ Model 2b. Women } \\
\hline & Coeff. & Std. Err. & Coeff. & Std. Err. & Coeff. & Std. Err. & Coeff. & Std. Err. \\
\hline \multicolumn{9}{|l|}{ Individual level } \\
\hline Age & $0.150^{* * *}$ & 0.007 & $0.192^{* * *}$ & 0.008 & $0.149^{* * *}$ & 0.007 & $0.192^{* * *}$ & 0.008 \\
\hline $\mathrm{Age}^{2}$ & $-0.013^{\star \star *}$ & 0.003 & $-0.007^{\star *}$ & 0.003 & $-0.013^{\star * *}$ & 0.003 & $-0.007^{\star \star}$ & 0.002 \\
\hline \multicolumn{9}{|l|}{ Ethnicity (ref=White British) } \\
\hline White Irish/White Other & 0.047 & 0.190 & $0.346^{*}$ & 0.177 & 0.054 & 0.189 & $0.352^{*}$ & 0.177 \\
\hline Mixed & 0.032 & 0.184 & -0.121 & 0.165 & 0.034 & 0.184 & -0.119 & 0.165 \\
\hline Asian & $-0.303^{* *}$ & 0.095 & $0.306^{* * *}$ & 0.088 & $-0.315^{\star * *}$ & 0.095 & $0.296^{\star * *}$ & 0.087 \\
\hline Black & -0.381 & 0.268 & -0.379 & 0.242 & -0.388 & 0.268 & -0.396 & 0.243 \\
\hline Other & -0.090 & 0.163 & -0.203 & 0.164 & -0.092 & 0.163 & -0.207 & 0.164 \\
\hline LLTI & $-0.459^{* * *}$ & 0.094 & $-0.304^{* * *}$ & 0.081 & $-0.462^{* * *}$ & 0.094 & $-0.300^{* * *}$ & 0.081 \\
\hline Degree & $0.306^{\star * *}$ & 0.044 & $0.341^{\star * *}$ & 0.043 & $0.307^{\star \star \star}$ & 0.044 & $0.339^{\star \star \star}$ & 0.043 \\
\hline Lived with child in 2001 & $-0.519^{* \star *}$ & 0.133 & $-1.034^{\star * *}$ & 0.068 & $-0.517^{* * *}$ & 0.133 & $-1.034^{* * *}$ & 0.068 \\
\hline Live with child in 2011 & $0.310^{* * *}$ & 0.049 & $0.319^{* * *}$ & 0.043 & $0.310^{* * *}$ & 0.049 & $0.319^{* * *}$ & 0.043 \\
\hline Lived with parent in 2001 & $-0.204^{* *}$ & 0.065 & -0.101 & 0.058 & $-0.207^{* *}$ & 0.065 & -0.104 & 0.058 \\
\hline Live with other adult in 2011 & $-1.287^{* * *}$ & 0.059 & $-1.249^{\star * \star}$ & 0.066 & $-1.286^{\star * *}$ & 0.059 & $-1.248^{* * *}$ & 0.066 \\
\hline Lived with partner in 2001 & 0.102 & 0.090 & $0.240^{* * *}$ & 0.062 & 0.099 & 0.090 & $0.237^{\star * *}$ & 0.062 \\
\hline \multicolumn{9}{|c|}{ Partnership and labour force position in 2011 (ref=couple, both working, NS-SEC 1-2) } \\
\hline Single, working, NS-SEC 1-2 & $-1.510^{\star * *}$ & 0.058 & $-1.662^{* * *}$ & 0.055 & $-1.511^{* * *}$ & 0.058 & $-1.661^{* * *}$ & 0.055 \\
\hline Single, working, NS-SEC 3-4 & $-1.931^{\star \star *}$ & 0.079 & $-2.120^{\star \star \star}$ & 0.073 & $-1.930^{\star \star *}$ & 0.079 & $-2.116^{\star \star *}$ & 0.073 \\
\hline Single, working, NS-SEC 5-7 & $-2.198^{\star * *}$ & 0.072 & $-2.837^{\star \star \star}$ & 0.091 & $-2.193^{\star * *}$ & 0.072 & $-2.835^{\star * *}$ & 0.091 \\
\hline Single, not working & $-3.421^{\star \star *}$ & 0.133 & $-3.682^{\star \star \star}$ & 0.107 & $-3.418^{\star * *}$ & 0.133 & $-3.675^{\star \star *}$ & 0.107 \\
\hline Couple, both working, NS-SEC 3-4 & $-0.300^{* * *}$ & 0.065 & $-0.253^{* * *}$ & 0.061 & $-0.299^{* * *}$ & 0.065 & $-0.251^{* * *}$ & 0.061 \\
\hline Couple, both working, NS-SEC 5-7 & $-0.899^{* * *}$ & 0.083 & $-0.699^{* * *}$ & 0.083 & $-0.894^{\star * *}$ & 0.082 & $-0.693^{* * *}$ & 0.083 \\
\hline Couple, one working, NS-SEC 1-2 & $-0.785^{\star * *}$ & 0.084 & $-0.528^{* * *}$ & 0.081 & $-0.783^{* * *}$ & 0.085 & $-0.536^{\star * *}$ & 0.081 \\
\hline Couple, one working, NS-SEC 3-4 & $-1.213^{\star \star \star}$ & 0.111 & $-0.908^{\star \star \star}$ & 0.098 & $-1.210^{\star \star \star}$ & 0.111 & $-0.907^{\star * \star}$ & 0.098 \\
\hline Couple, one working, NS-SEC 5-7 & $-1.692^{* * *}$ & 0.095 & $-1.536^{* * *}$ & 0.085 & $-1.687^{* * *}$ & 0.095 & $-1.525^{\star * *}$ & 0.085 \\
\hline Couple, neither working & $-3.196^{\star \star \star}$ & 0.198 & $-3.108^{* \star *}$ & 0.153 & $-3.189^{\star * *}$ & 0.198 & $-3.099^{* * *}$ & 0.153 \\
\hline Moved $>=30 \mathrm{~km} \mathrm{1991-2001}$ & 0.012 & 0.066 & -0.044 & 0.059 & 0.016 & 0.066 & -0.044 & 0.059 \\
\hline Moved $>=30 \mathrm{~km}$ 2001-2011 & $-0.266^{* * *}$ & 0.050 & $-0.328^{* * *}$ & 0.047 & $-0.268^{* * *}$ & 0.050 & $-0.323^{* * *}$ & 0.047 \\
\hline
\end{tabular}


Regional fixed effects (ref=South East)

\begin{tabular}{|c|c|c|c|c|c|c|c|c|}
\hline North East & -0.025 & 0.117 & 0.134 & 0.121 & -0.007 & 0.117 & 0.164 & 0.121 \\
\hline North West & $-0.303^{\star \star \star}$ & 0.091 & -0.083 & 0.093 & $-0.290^{* *}$ & 0.091 & -0.056 & 0.093 \\
\hline Yorkshire and the Humber & -0.130 & 0.094 & 0.066 & 0.097 & -0.113 & 0.094 & 0.090 & 0.097 \\
\hline East Midlands & -0.043 & 0.094 & -0.007 & 0.094 & -0.028 & 0.094 & 0.015 & 0.094 \\
\hline West Midlands & -0.157 & 0.090 & $-0.220^{*}$ & 0.091 & -0.149 & 0.091 & $-0.206^{*}$ & 0.091 \\
\hline East of England & -0.105 & 0.075 & 0.000 & 0.076 & -0.103 & 0.076 & 0.002 & 0.076 \\
\hline London & -0.085 & 0.104 & -0.050 & 0.106 & -0.086 & 0.104 & -0.051 & 0.106 \\
\hline South West & $-0.167^{\star}$ & 0.081 & -0.114 & 0.081 & $-0.168^{*}$ & 0.081 & -0.115 & 0.081 \\
\hline Wales & -0.077 & 0.107 & -0.077 & 0.107 & -0.057 & 0.107 & -0.050 & 0.107 \\
\hline Ige gap with younger parent & -0.002 & 0.004 & 0.003 & 0.004 & -0.002 & 0.004 & 0.003 & 0.004 \\
\hline \multicolumn{9}{|l|}{ District level } \\
\hline opulation density & $0.011^{* * *}$ & 0.002 & $0.011^{\star \star *}$ & 0.002 & $0.011^{* * *}$ & 0.002 & $0.011^{* * *}$ & 0.002 \\
\hline o social tenants & $-0.015^{\star \star}$ & 0.005 & $-0.015^{\star *}$ & 0.005 & $-0.015^{\star *}$ & 0.005 & $-0.014^{\star *}$ & 0.005 \\
\hline private tenants & $-0.038^{* \star *}$ & 0.006 & $-0.030^{* * *}$ & 0.006 & $-0.038^{* * *}$ & 0.006 & $-0.030^{* * *}$ & 0.006 \\
\hline \multicolumn{9}{|l|}{ nteracted variables } \\
\hline n median district house price & $-0.524^{\star * *}$ & 0.088 & $-0.567^{\star * *}$ & 0.091 & $-0.588^{\star * *}$ & 0.083 & $-0.691^{* * *}$ & 0.085 \\
\hline \multicolumn{9}{|c|}{ arental labour force position (ref=working, NS-SEC 1-2) } \\
\hline Working, NS-SEC 3-4 & -0.086 & 0.048 & -0.027 & 0.047 & -0.090 & 0.048 & -0.038 & 0.047 \\
\hline Working, NS-SEC 5-7 & $-0.178^{* * *}$ & 0.052 & $-0.258^{* * *}$ & 0.050 & $-0.150^{* *}$ & 0.051 & $-0.250^{* * *}$ & 0.049 \\
\hline Workless & $-0.151^{*}$ & 0.070 & $-0.235^{\star * *}$ & 0.066 & $-0.164^{*}$ & 0.069 & $-0.216^{* * *}$ & 0.064 \\
\hline \multicolumn{9}{|c|}{ House price x parental labour force position } \\
\hline Price $x$ working, NS-SEC 3-4 & -0.113 & 0.095 & $-0.271^{\star *}$ & 0.097 & & & & \\
\hline Price $x$ working, NS-SEC 5-7 & $-0.291^{* *}$ & 0.109 & $-0.314^{* *}$ & 0.103 & & & & \\
\hline Price $\mathrm{x}$ workless & -0.035 & 0.129 & $-0.484^{* * *}$ & 0.123 & & & & \\
\hline arental tenancy & $-0.549^{\star \star \star}$ & 0.051 & $-0.605^{\star * *}$ & 0.048 & $-0.560^{* * *}$ & 0.052 & $-0.621^{* * *}$ & 0.048 \\
\hline Price $x$ parental tenancy & & & & & -0.070 & 0.101 & $-0.216^{*}$ & 0.093 \\
\hline Constant & $1.316^{\star \star *}$ & 0.097 & $1.284^{* \star *}$ & 0.091 & $1.319^{\star \star \star}$ & 0.097 & $1.289^{\star * *}$ & 0.091 \\
\hline ariance of district random effect (null) & \multicolumn{2}{|c|}{$0.011(0.090)$} & \multicolumn{2}{|c|}{$0.019(0.099)$} & \multicolumn{2}{|c|}{$0.012(0.090)$} & \multicolumn{2}{|c|}{$0.020(0.099)$} \\
\hline ariance Partition Coefficient (null) & \multicolumn{2}{|c|}{$0.003(0.027)$} & \multicolumn{2}{|c|}{$0.006(0.029)$} & \multicolumn{2}{|c|}{$0.004(0.027)$} & \multicolumn{2}{|c|}{$0.006(0.029)$} \\
\hline 3ayesian Information Criterion (null) & \multicolumn{2}{|c|}{$19421.280(27099.179)$} & \multicolumn{2}{|c|}{$20858.918(30238.591)$} & \multicolumn{2}{|c|}{$19408.496(27099.179)$} & \multicolumn{2}{|c|}{20855.561 (30238.591) } \\
\hline cases (districts) & \multicolumn{2}{|c|}{$20230(347)$} & \multicolumn{2}{|c|}{$22080(347)$} & \multicolumn{2}{|c|}{$20230(347)$} & \multicolumn{2}{|c|}{22080 (347) } \\
\hline
\end{tabular}

Source: ONS LS, own analysis. ${ }^{* *}=p<0.001^{* *}=p<0.01^{*}=p<0.05$. Grand mean centred continuous predictors. LLTI=limiting long-term illness/disability. 


\begin{tabular}{|c|c|c|}
\hline Categorical variables & Men (column \%) & Women (column \%) \\
\hline \multicolumn{3}{|l|}{ Ethnicity } \\
\hline White British (ref) & 90.6 & 90.3 \\
\hline White Irish/White Other & 1.0 & 1.1 \\
\hline Mixed & 1.1 & 1.4 \\
\hline Asian & 5.0 & 5.0 \\
\hline Black & 0.8 & 0.9 \\
\hline Other ethnicity & 1.5 & 1.3 \\
\hline Long-term limiting health problem/disability $(r e f=n o)$ & 6.3 & 6.8 \\
\hline Degree level qualifications $(r e f=n o)$ & 39.4 & 44.1 \\
\hline Lived with own child in 2001 (ref=no) & 2.3 & 11.1 \\
\hline Lives with own child (ref=no) & 26.4 & 47.2 \\
\hline Lived with parent in 2001 (ref=no) & 77.7 & 65.0 \\
\hline Lives with other adult (ref=no) & 24.1 & 15.0 \\
\hline Lived with partner in 2001 (ref=no) & 7.9 & 16.6 \\
\hline \multicolumn{3}{|l|}{ Partnership and labour force position in 2011} \\
\hline Single, working, NS-SEC 1-2 & 16.5 & 14.4 \\
\hline Single, working, NS-SEC 3-4 & 8.4 & 7.9 \\
\hline Single, working, NS-SEC 5-7 & 13.5 & 7.4 \\
\hline Single, not working & 8.6 & 10.3 \\
\hline Couple, both working, NS-SEC 1-2 (ref) & 29.2 & 32.6 \\
\hline Couple, both working, NS-SEC 3-4 & 8.1 & 9.6 \\
\hline Couple, both working, NS-SEC 5-7 & 4.2 & 4.0 \\
\hline Couple, one working, NS-SEC 1-2 & 3.9 & 4.3 \\
\hline Couple, one working, NS-SEC 3-4 & 2.2 & 2.6 \\
\hline Couple, one working, NS-SEC 5-7 & 3.6 & 4.2 \\
\hline Couple, workless & 1.8 & 2.6 \\
\hline Moved >=30km 1991-2001 (ref=no) & 15.2 & 16.2 \\
\hline Moved >=30km 2001-2011 (ref=no) & 22.3 & 23.3 \\
\hline \multicolumn{3}{|l|}{ Region } \\
\hline North East & 5.1 & 5.0 \\
\hline North West & 13.0 & 12.7 \\
\hline Yorkshire and the Humber & 9.7 & 10.1 \\
\hline East Midlands & 7.9 & 8.4 \\
\hline West Midlands & 10.1 & 10.2 \\
\hline East of England & 10.7 & 10.5 \\
\hline London & 13.5 & 12.9 \\
\hline South East (ref) & 15.1 & 15.1 \\
\hline South West & 9.3 & 9.6 \\
\hline Wales & 5.4 & 5.6 \\
\hline \multicolumn{3}{|l|}{ Parental labour force position in 1991} \\
\hline Working, NS-SEC 1-2 (ref) & 37.2 & 34.9 \\
\hline Working, NS-SEC 3-4 & 24.5 & 23.5 \\
\hline Working, NS-SEC 5-7 & 25.3 & 26.1 \\
\hline Workless & 13.0 & 15.5 \\
\hline Parental tenancy in 1991 (ref=owner-occupation) & 22.1 & 25.2 \\
\hline Continuous variables & Mean (std. dev.) & Mean (std. dev.) \\
\hline Age & $29.2(2.9)$ & $29.3(2.9)$ \\
\hline Age gap with youngest parent in 1991 & $27.2(5.0)$ & $27.0(5.1)$ \\
\hline$\%$ social tenant households in district & $17.9(7.0)$ & $17.9(6.9)$ \\
\hline$\%$ private tenant households in district & $18.0(5.8)$ & $17.9(5.7)$ \\
\hline Population density (persons/Ha) of district & $21.6(26.7)$ & $21.0(26.1)$ \\
\hline Ln median terraced house price in district & $11.9(0.5)$ & $11.9(0.5)$ \\
\hline $\mathrm{N}$ cases & 20230 & 22080 \\
\hline
\end{tabular}

Source: ONS LS, own analysis. Variables measured in 2011 unless stated. Students are coded as not working in the indicators of labour force position. 